\title{
AGING WORK FORCE - THE HR PERSPECTIVE
}

* MS. MANISHA SHARMA

\begin{abstract}
The world population is aging day by day. The young-old balance is shifting throughout the world. In the total population throughout the world, the composition of population aged 0-14 and 15-25 is decreasing and that of people falling in the bracket of $25-60$ and $60+$ is increasing. The developed regions of the World such as UK, USA, Japan and Australia etc. are already at the mercy of the old aged population where aged population is exceeding the no. of young population since 2000. By 2050, the proportion of aged population is projected to increase to app. $34 \%$ in these countries. So far as less and the least developed regions of the world are concerned, the situation is not so tense at present but it is estimated that the gap between young and aged population will be wider by 2050 . Hence these regions also need to take effective measures right now to deal with the consequences of such a situation in the near future. In such a scenario, the composition of workforce shall also be changing world wide with more number of aged people working at different levels in the corporate sector. This has also opened a new dimension for the HR people as well as for the aged population. Most of the aged people were earlier on living a retarded and dependent life. Now the World is looking at them for an active role to play. Even the aged people themselves are also now interested in contributing to the society and the economy as an active partner. At the same time, the problem of corporate regarding recruitment is also solved to some extent as a new source of recruitment is explored. But this workforce looks at corporate for fulfilling their own special needs regarding retirement, healthcare, flextime work arrangements etc. in a more explorative way. This paper gives an insight into the various aspects of the aging workforce from the organizational point of view as well as the aged population's point of view. Hence this study is not only important for the organizations which are looking at the aged population for the recruitment purposes but also for the aged population who wants to take an active part in the society.
\end{abstract}

In all the nations of the World whether they are more developed, less developed or least developed, the composition of aged population in the total population is increasing day by day. Declining birth rates and increasing life expectancy are the main reasons behind this demographic transition. The birth rate has declined from 37.4 per thousand population in 1950-55 to 21.1 per thousand population in 2000-05 and it is projected to further decline to 13.6 per thousand population by 2045-50. Even the total fertility rate throughout the World is also declining. According to the UN Population division during the last 50 years, the total fertility rate in the World decreased from 5.0 to 2.7 children per woman. Over the next 50 years, it is expected to even drop more i.e. app. 2.1 children per women. Most of the young population not interested in increasing their family size due to nuclear family problems and increasing expenditures are contributing to low fertility and death rates. At the same time, adequate medical

* Freelance Researcher,

H.No.24, St.No.5, Guru Gobind Singh Nagar (East), Majitha Road, P.O. Khanna Nagar, Amritsar, Punjab, India. Tel : 09988488500 
facilities are increasing the life expectancy and hence declining the death rates. According to UN Population Division, Life expectancy has increased from 46.5 years to 66 years over the last half century and it is projected to increase to 76 years by the next half century. So far as India is concerned, the problem is not that acute as compared to the more developed regions of the world such as UK, USA, Australia and Canada etc. But it won't take much time for India to face this problem. Lets have a look at the World ageing as well as India's ageing.

\section{EXHIBIT-1}

\begin{tabular}{|l|l|l|l|c|}
\hline & Major Areas & $1950-55$ & $2000-05$ & $2045-50$ \\
\hline $\begin{array}{l}\text { Crude Birth Rates (births } \\
\text { per 1000 population) }\end{array}$ & World & 37.4 & 21.1 & 13.6 \\
\hline & More Developed Regions & 22.4 & 11.1 & 10.0 \\
\hline & Less developed Regions & 44.3 & 23.5 & 14.2 \\
\hline & Least Developed Regions & 49 & 37.6 & 20.6 \\
\hline & India & 43.3 & 25.1 & 12.3 \\
\hline
\end{tabular}

Source: Population Division of the Department of Economic and Social Affairs of the United Nations Secretariat (2007), World Population Prospects: The 2006 Revision and World Urbanization prospects: The 2005 revision.

As is clear from the above table, the crude birth rates are declining throughout the World including India at sharp rate. Rather in India it is declining at a fast rate as compared to different regions of the World. The main reason behind this is the reluctance of young generation to increase family due to nuclear family problems and increasing expenditure. On the other hand, Life expectancy is increasing as is reflected in exhibit-2

\section{EXHIBIT-2}

\begin{tabular}{|l|l|l|l|l|}
\hline & Major Areas & $1950-55$ & $2000-05$ & $2045-50$ \\
\hline $\begin{array}{l}\text { Life Expectancy (births per } \\
1000 \text { population) }\end{array}$ & World & 46.4 & 66 & 75.4 \\
\hline & More Developed Regions & 66.1 & 75.6 & 82.4 \\
\hline & Less developed Regions & 40.8 & 64.1 & 74.3 \\
\hline & Least Developed Regions & 36.2 & 52.7 & 67.2 \\
\hline & India & 37.4 & 62.9 & 75.6 \\
\hline
\end{tabular}

Source: Population Division of the Department of Economic and Social Affairs of the United Nations Secretariat (2007), World Population Prospects: The 2006 Revision and World Urbanization prospects: The 2005 revision. 
Due to this decrease in birth rate and increase in life expectancy, the composition of aging population is increasing in total population as is reflected in exhibit -3 .

\section{EXHIBIT-3}

\begin{tabular}{|l|c|c|c|c|c|c|c|c|}
\cline { 2 - 9 } \multicolumn{1}{c|}{} & \multicolumn{4}{c|}{ Population in the year 2005 } & \multicolumn{4}{c|}{ Population in the year 2050 } \\
\hline Major Areas & $0-14$ & $15-24$ & $25-59$ & $60+$ & $0-14$ & $15-24$ & $25-59$ & $60+$ \\
\hline World & 28.3 & 17.9 & 43.5 & 10.3 & 19.8 & 13.4 & 44.9 & 21.8 \\
\hline $\begin{array}{l}\text { More } \\
\text { Developed } \\
\text { Regions }\end{array}$ & 17 & 13.7 & 49.2 & 20.1 & 15.2 & 10.6 & 41.6 & 32.6 \\
\hline $\begin{array}{l}\text { Less } \\
\text { Developed } \\
\text { Regions }\end{array}$ & 30.9 & 18.9 & 42.1 & 8.1 & 20.6 & 13.8 & 45.5 & 20.1 \\
\hline $\begin{array}{l}\text { Least } \\
\text { Developed } \\
\text { Regions }\end{array}$ & 41.5 & 20.2 & 33.2 & 5.1 & 28.2 & 17.8 & 43.7 & 10.3 \\
\hline India & 33 & 19.3 & 40.3 & 7.5 & 18.2 & 12.7 & 48.9 & 20.2 \\
\hline
\end{tabular}

Source: Population Division of the Department of Economic and Social Affairs of the United Nations Secretariat (2007), World Population Prospects: The 2006 Revision and World Urbanization prospects: The 2005 revision

We can see that composition of population aged 25-59 and population aged $60+$ is increasing in the World's population. Similar is the case with India. In case of India, the composition of population aged $0-14$ and $15-24$ is decreasing i.e. from $33 \%$ in 2005 to $18.2 \%$ in 2050 and from 19.3 $\%$ in 2005 to $12.7 \%$ in 2050 respectively. Whereas the composition of population aged 25-59 and 60+ is increasing at a faster rate. It means in the total population, the composition of aged population is increasing and that of young population is decreasing.

This increasing aged population, whereas, on one hand is putting economic pressures on the economy and on the other hand has emerged as a prospective labourforce for the corporates who constantly search for the experienced and matured employees.

\section{HR Perspective:}

The HR perspective of this demographic change will be the change in the composition of workforce having more no. of aged and experienced people as compared to the young people. But whether is there a need for the older or aged workforce? Whether companies really need to look into HR perspective of such a scenario? The answer lies in the following questions. The companies should probably ask themselves the following questions:

- What can be our company's key human resource requirements in the next 10 to 20 years?

- Do we know our employees' demographics?

- What type of risks regarding key positions or job categories, our company may have to face in future?

- Has our company identified potential opportunities for attracting and retaining mature workers using part-time or alternative work arrangements? 
- Does our company have a strategy in place to preserve critical knowledge before it walks out the door?

- How effectively are we addressing the age-related issues within our company's overall diversity strategy?

If a company can answer these questions, they shall definitely be saying that the aged people shall be a part of their company's workforce in the near future. Hence it becomes essential for them to have a look on the needs of such type of workforce. This type of workforce shall be more inclined towards flextime work arrangements, medical benefits and other post retirement benefits. Therefore, companies can no longer consider these benefits as optional facilities for employees. According to a report prepared by global HR consultants firm Watson Wyatt, a welldesigned retirement and healthcare scheme will greatly enhance the ability of companies to attract and retain the most qualified and competent employees. As global competition intensifies amongst companies, human capital strategies that take into account demographic changes will be crucial to ensure the sustained corporate profitability.

\section{Addressing the aging workforce:}

Companies should consider a number of potential strategies for addressing the aging workforce. It includes

\section{- Part-time and other alternative working arrangements:}

Many companies, in order to overcome the shortage of skilled workforce are encouraging its older employees to work even after their traditional retirement age. A no. of studies conducted over the past decade have also found that most older workers in the World are actively considering their options to remain in the workforce even after formal retirement. According to a survey by AARP, $80 \%$ of older workers of U.S. who will soon reach the "normal retirement age" want to continue to work. In addition to it, a survey conducted by the Society of Human Resource Management (SHRM) in U.S. reflected that two thirds $(68 \%)$ of the workplaces under survey reported that they have the retiree employees of other organizations. Their workforces included employees who had retired from other organizations (Collinson, 2003:7). Merill Lynch has conducted a survey on the Baby boomer generation (i.e., people born between 1946 and 1964) and found that most of the older workers wanted to continue to work in one way or the other. Only $6 \%$ of the older workers wanted to work as full-time employees. On the other hand, $16 \%$ of the older workers wanted to work for part time and other alternative work arrangements.

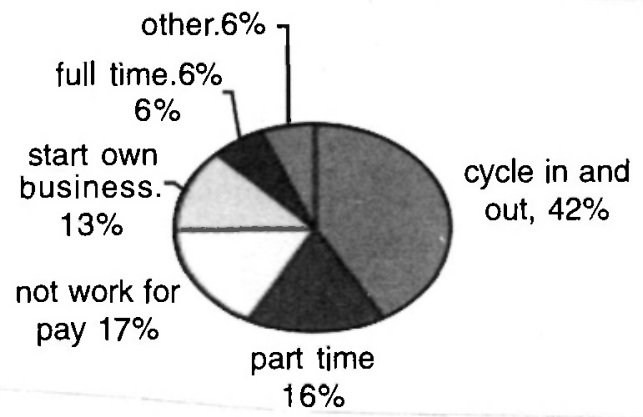

Source: Merrill Lynch cited in Varchaver, 2005

The Corporates are also not unaware of it. This is the reason why are they offering part- time and flextime work arrangements to their employees. They are hence ready to provide them with alternative work arrangements in order to retain them in the workforce and make use of their experience and intelligence for longer. A recent study conducted by Hudson group also reveals that about $70 \%$ of managers in Australia are interested in providing alternative and part-time work arrangements to its employees in order to retain them. Aerospace Company of U.S. has also developed a Retiree Casual Program for its retired and retiring employees. In this Programme, the retired employees of the company are offered to work on a 
Project Consulting basis for up to 1000 hours p.a.. By doing so, they can earn near about the same basic salary as they were earning before retirement depending on the job profile they choose. About 200 retirees are already working under this Programme and both,the company as well as the employees are getting benefitted.

\section{- Supplementary retirement and healthcare:}

Aged people are generally more prone to health related problems as compared to their younger counter-parts. Hence they tend to assign more weightage to a job which is providing them with more supplementary healthcare benefits as compared to any other job. A survey conducted by WHO in 2008 also reflects that out of all concerns, people give more importance to their healthcare as is reflected in the figure given below:

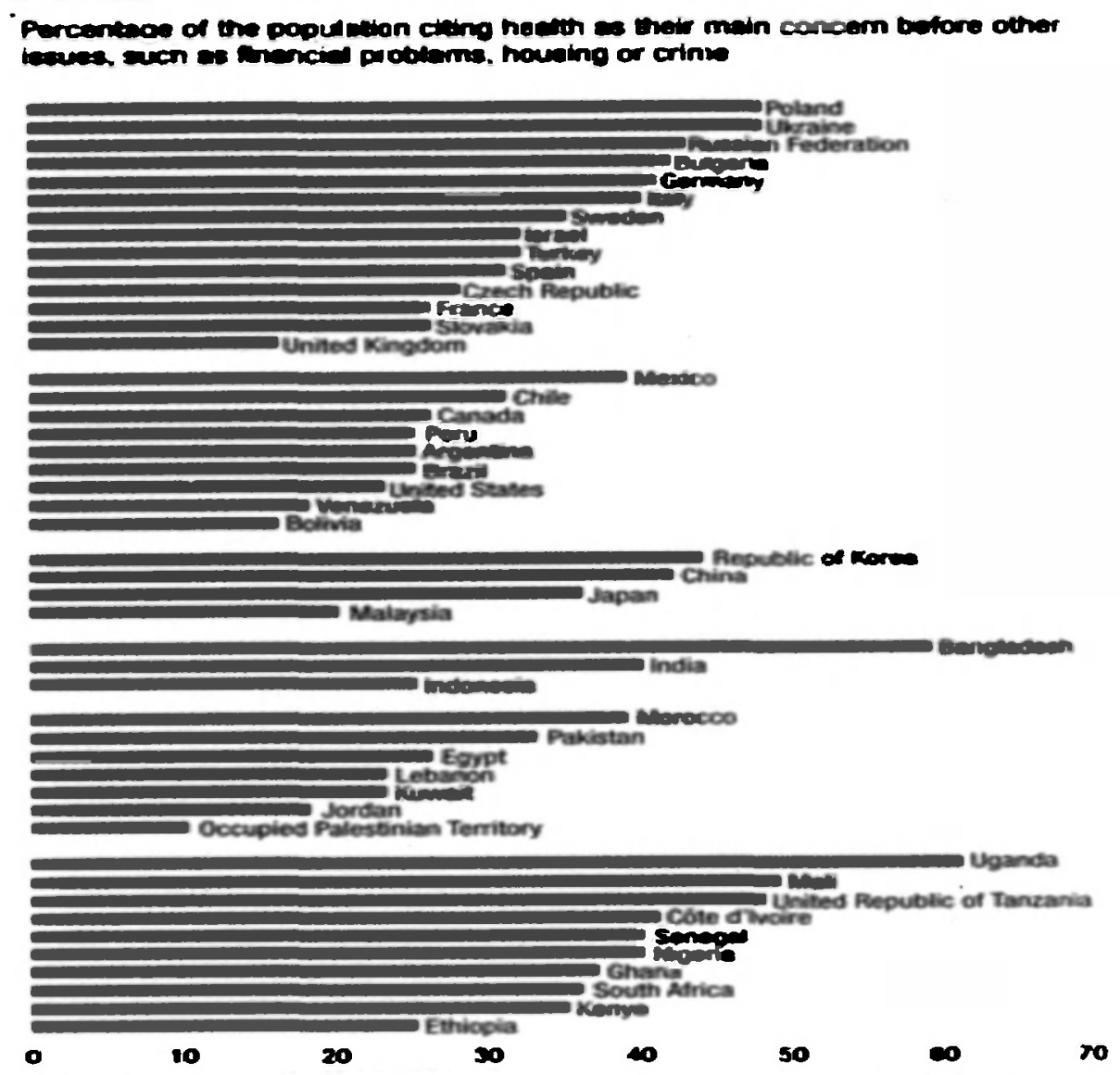

Source: http://www.who.int/whr/2008/media_centre/tables_figures/en/index1.html

Hence it quite clear that if people give preference to healthcare over and above other concerns, they shall also be preferring the jobs who are providing them the same. Employers are not unaware of it. What they are looking for is the alternative ways to reduce the costs which such expenditures will incur to their company. Normally employers do not look at providing these benefits to its employees as their moral responsibility. In a study conducted by Watson Wyat on the employers, only $26 \%$ of employers across Asia Pacific believe that they have any responsibility (ranging from only $5 \%$ in Singapore to $56 \%$ in India and the Philippines) of paying such retirement and healthcare benefits to its employees. The fulfillment of this need of ageing workforce 
also brings in other major issue i.e. healthcare costs. India is also widely referred to as the capital of diabetes and heart diseases. Both are chronic diseases and require lifelong and costly treatment. While the present healthcare facilities are inadequate, the government and corporates have to come out with a solution so that productivity does not suffer. With government's budget already stretched. it is for the corporates to devise schemes to take care of their employees' healthcare if they want to attract talent especially the older ones.

\section{- Preserving critical knowledge before it leaves the organization:}

Matured and experienced employees are the valuable assets of any company. When such employees leave any company, they take away with them all the knowledge and the earned experience of years to tackle different difficult situations in that company. Such knowledge can range from written notes and reports to experience and skills which an employee would have earned in his due course of employment to do his job effectively. Hence when he leaves the company, such knowledge also leaves the company. Company suffers a huge but uncountable and indirect loss. The company could have made a better use of this knowledge by training new empioyees who keep on searching the answers of the questions which have already been answered by the previous employees. Hence lots of time is wasted in finding the solutions for the problems which have already been solved by someone else. They simply fail to learn from the lessons which have been previously learned but were never formally identified and captured.

Many firms have recognized this phenomenon and started looking for alternative ways to stop this hemorrhage of corporate insight. Many Intelligent firms have already find solution to this problem by the means of

\section{Knowledge elicitation Techniques}

2. Knowledge exchange techniques.

With the help of Knowledge elicitation techniques the employers try to attain and retain the basic knowledge in the formats that other employees can easily access. The World Bank has done a remarkable job in this field. It has captured and stored the videos and audios of its certain individuals and groups handling difficult and challenging projects throughout the world. Then it uses them to train the new and the remaining employees and group in order to improve the quality of the product. The Bank also make use of storytelling techniques by the interviewees in order to make the things interesting for the intended audience. These knowledge elicitation techniques have been admired by the concerned audiences a lot.

On the other hand, with the help of Knowledge exchange techniques, employers try to facilitate communication among the employees so that they can share knowledge which otherwise cannot be captured and stored. In addition to this, some organizations aie working with the Knowledge exchange techniques. An Australian company, West Australian Petroleum Proprietary Limited has developed an effective system of transferring knowledge and experience of its incumbents to their replacements. The company tries to find out a good employee who could replace the future retiree at least three months prior to his/her retirement. The schedule of the retiring employee is changed at the same salary during these last three months of his job. The retiring employee is asked to instruct his successor till the time his successor becomes capable of undertaking full responsibility of his job. In this way, the incumbent shares his knowledge and experience with the person replacing him easily, which otherwise, might have been forfeited by the retiring employee. 


\section{- Retraining the older workers:}

In order to get efficient work from the aged and the matured section of their workforce, Companies need to retrain them. Hence they should make arrangements for appropriate educational opportunities and training seminars for them in order to update their knowledge and skill base. In some cases, universities and the public sectors are taking the lead in providing retraining opportunities and assistance for the matured segment of the workforce. The University of Sydney offers an 18month Accelerated Teacher Training degree program for the older scientists, engineers, and the IT experts. In other situations, private industry is providing training for individuals interested in second or third careers. Westpac has also provided the facility of training up to 900 recruits who are over 55 years of age in order to increase its presence in the financial advising market. Noel Purcell, Westpac's General Manager of stakeholder communications, has noted that the older workers are an important asset of their company. It is so because they relate well with the older customers who sometimes feel that younger staff is not experienced enough to address their financial concerns.

\section{- Facilitating the productive coexistence of a multigenerational workforce:}

The increasing composition of aging workforce with the younger workforce will pave the way of coexistence of multigenerational workforce at the working places. Hence If the organizations want that their older workforce could give their best at the workplace, they will have to provide certain facilities to them to have their productive coexistence. When individuals think about diversity challenges, age is not always one of the delineations that struck to mind. The perceptions and beliefs of different age groups may present significant barriers where age span is fifty years or even more. In order to raise the morale of the employees and discourage early attrition, companies need to provide facilities to have their productive usage.
Many organizations are actively working to solve such issues of multigenerational workforce. A study conducted by Australia Post was also aimed at understanding its changing workforce demographics and the needs and perceptions of both younger and mature workers. It also suggested the ways on how the organization could better capitalize on the capabilities of each group. For more details, one can visit

http://www.humanresourcesmagazine.com.au/ articles $/ 5 \mathrm{E} / 0 \mathrm{C} 02515 \mathrm{E}$. asp?Type $=60 \&$ Category $=903$

Many Companies nowadays are looking for different ways to bring together older and younger workers to make best use of their respective talents and to have to more understanding and coordination among them. To serve this purpose, General Electric Company provided training to its 500 senior managers and junior employees. The training was aimed at learning about the new Internet technologies. It paired the "junior" and the "senior" mentors on the basis of their knowledge and personality traits during training. They spent approximately 2 to 4 hours together on week basis to learn the ins and outs of WWW i.e. World Wide Web. This exercise not only helped the senior managers to gain an insight of their business moving to an Internet age but also helped the junior executives to meet the seniors which otherwise could not have been easy for them to do.

\section{CONCLUSION}

In nutshell, the greatest HR challenge of the coming decades of the Corporate sector will be to enhance the productivity of their workforce as the availability of young skilled workers will decline. It will make them to look for the aging and experienced employees for the want of skilled employees and to meet their HR needs. As the time advances, companies will soon realize the pains associated 
with losing expertise, demographic changes of the available workforce, higher recruiting and training costs and managing intergenerational concerns etc. Hence they need to take a proactive approach to address these demographic changes, both within their organizations and across their labor markets, if they wish to avoid issues that could significantly hamper their progress in the highly competitive and dynamic industrialized world in the near future.

\section{Terms used (Definitions are as defined by UN Population Division)}

\section{More developed regions :}

These comprise all regions of Europe plus Northern America, Australia/New Zealand and Japan.

\section{Less developed regions:}

These comprise all regions of Africa, Asia (excluding Japan) and Latin America and the Caribbean, as well as Melanesia, Micronesia and Polynesia.

\section{Least developed regions:}

The group of least developed countries currently comprises 50 countries: Afghanistan, Angola, Bangladesh, Benin, Bhutan, Burkina Faso, Burundi, Cambodia, Cape Verde, Central African Republic, Chad, Comoros, Democratic Republic of the Congo, Djibouti, Equatorial Guinea, Eritrea, Ethiopia, Gambia, Guinea, Guinea-Bissau, Haiti, Kiribati, Lao People's Democratic Republic, Lesotho, Liberia, Madagascar, Malawi, Maldives, Mali, Mauritania, Mozambique, Myanmar, Nepal, Niger, Rwanda, Samoa, São Tomé and Príncipe, Senegal, Sierra Leone, Solomon Islands, Somalia, Sudan, TimorLeste, Togo, Tuvalu, Uganda, United Republic of Tanzania, Vanuatu, Yemen and Zambia.

\section{REFERENCES}

a) Population Division of the Department of Economic and Social Affairs of the United Nations Secretariat (2007), World Population Prospects: The 2006 Revision

b) Population Division of the Department of Economic and Social Affairs of the United nations Secretariat (2007), World Urbanization prospects: The 2005 revision

c) William C. Cockerham., This aging society; Prentice-Hall Inc. publication company, New Jersey, 1991.

d) Paul D Chowdhary., Aging \& the aged, a source book; Inter-India publication, New Delhi,1992

e) http://

www.humanresourcesmagazine.com.au/ articles/5E 0C02515E.asp?Type $=60 \&$

Category $=903$

f) www.globalaging.org/elderrights/world/2006/ ageingworkforceap.pdf

g) http://www.who.int/whr/2008/media_centre/ tables_figures/en/index1.html 